\title{
Corrosion behavior of ultrafine-grained AA2024 aluminum alloy produced by cryorolling
}

\author{
P. Laxman Mani Kanta ${ }^{1)}$, V.C. Srivastava ${ }^{2)}$, K. Venkateswarlu ${ }^{3)}$, Sharma Paswan ${ }^{2)}$, B. Mahato ${ }^{2)}$, \\ Goutam Das $^{2}$, K. Sivaprasad $^{1)}$, and K. Gopala Krishna ${ }^{2)}$ \\ 1) Department of Metallurgical \& Materials Engineering, National Institute of Technology, Thiruchirappalli 620015, India \\ 2) National Metallurgical Laboratory, Council of Scientific \& Industrial Research, Jamshedpur 831007, India \\ 3) National Aerospace Laboratories, Council of Scientific \& Industrial Research, Bangalore 560017, India \\ (Received: 20 January 2017; revised: 20 June 2017; accepted: 21 June 2017)
}

\begin{abstract}
The objectives of this study were to produce ultrafine-grained (UFG) AA2024 aluminum alloy by cryorolling followed by aging and to evaluate its corrosion behavior. Solutionized samples were cryorolled to $\sim 85 \%$ reduction in thickness. Subsequent aging resulted in a UFG structure with finer precipitates of $\mathrm{Al}_{2} \mathrm{CuMg}$ in the cryorolled alloy. The (1) solutionized and (2) solutionized and cryorolled samples were uniformly aged at $160^{\circ} \mathrm{C} / 24 \mathrm{~h}$ and were designated as CGPA and CRPA, respectively; these samples were subsequently subjected to corrosion studies. Potentiodynamic polarization studies in $3.5 \mathrm{wt} \% \mathrm{NaCl}$ solution indicated an increase in corrosion potential and a decrease in corrosion current density for CRPA compared to CGPA. In the case of CRPA, electrochemical impedance spectroscopic studies indicated the presence of two complex passive oxide layers with a higher charge transfer resistance and lower mass loss during intergranular corrosion tests. The improved corrosion resistance of CRPA was mainly attributed to its UFG structure, uniform distribution of fine precipitates, and absence of coarse grain-boundary precipitation and associated precipitate-free zones as compared with the CGPA alloy.
\end{abstract}

Keywords: AA2024 alloy; cryorolling; ultrafine grains; precipitation; corrosion behavior

\section{Introduction}

AA2024 is a high-strength $\mathrm{Al}-\mathrm{Cu}-\mathrm{Mg}$ alloy with a complex microstructure and numerous compositionally distinct phases such as $\mathrm{Al}_{2} \mathrm{CuMg}$ and $\mathrm{Al}_{7} \mathrm{CuFe}_{2}$ [1-2]. It has applications as the outer skin material for aircraft wings and fuselages [3-4]. The nature of the strengthening precipitates in the alloy is determined by the $\mathrm{Cu}$-to-Mg mass ratio; and for $\mathrm{Mg}$ contents greater than $1 \mathrm{wt} \%$, the precipitation of $\mathrm{S}^{\prime}$ and $\mathrm{S}$ phases $\left(\mathrm{Al}_{2} \mathrm{CuMg}\right)$ is observed [5]. The reported precipitation sequence for the alloy is as follows [6]: super saturated solid solution (SSSS) $\rightarrow$ solute clusters $\rightarrow$ Guinier-Preston-Bagaryatsky (GPB) zones $\rightarrow \mathrm{S}^{\prime \prime} \rightarrow \mathrm{S}^{\prime} \rightarrow \mathrm{S}$ phase.

Bulk ultrafine-grained (UFG) metals and alloys produced by severe plastic deformation (SPD) processes such as equal channel angular pressing (ECAP), high-pressure torsion, accumulative roll bonding, and twin extrusion have been demonstrated to exhibit increased strength with limited ductility [7]. Recently, rolling at cryogenic (liquid $\mathrm{N}_{2}$ ) temperature was found to result in high strains in the material by suppressing the dynamic recovery during deformation. This suppression can preserve a high density of defects, which can act as recrystallization sites for the formation of the UFG structure. This technique has been optimized for the production of ultrafine grains in materials with high-stacking-fault-energy such as aluminum because, in these materials, dynamic recovery occurs readily by the cross slip of dislocations during deformation itself. Hence, conventional rolling at cryogenic temperature (i.e., cryorolling) is considered a potential route to produce UFG materials [8-15]. Shanmugasundaram et al. [8] have demonstrated that a UFG material with improved tensile strength and good ductility can be produced by cryorolling an $\mathrm{Al}-\mathrm{Cu}$ 
alloy. Cryorolling followed by warm rolling of Al-Mn-Si alloy resulted in an alloy with substantially improved mechanical properties compared with those of cryorolled and short-annealed alloy samples, as reported by Rao et al. [11]. Short annealing and peak aging of cryorolled $\mathrm{Al}-4 \mathrm{Zn}-2 \mathrm{Mg}$ not only increased the alloy's strength but also retained its ductility because of the formation of UFG structure combined with finer strengthening precipitates [16]. Deep-cryogenic treatment drastically changed the mechanical properties of $\mathrm{Al}$ alloys by refining the grain size and altering the distribution of fine precipitates [17]. The overall effect of partial grain refinement, dislocation hardening, and dynamic aging during cryorolling and warm rolling resulted in increased strength and partially improved ductility in AA6061 alloy [10].

Although some authors have reported improvements in the mechanical properties of AA2024 Al alloy through SPD, studies on the corrosion behavior of these UFG alloys are limited. The heterogeneous microstructure of the AA2024 alloy with S-phase precipitates and coarse constituent particles is highly susceptible to localized corrosion [18-21]. Pitting occurs near the microconstituent particles because of discontinuity of the oxide film surrounding the particles, which enables the formation of a galvanic couple with the Al matrix in corrosive environments [18]. By contrast, intergranular corrosion (IGC) occurs via localized attack of the constituent particles aligned as a network along the grain boundaries. Corrosion of an alloy is particularly associated with structural inhomogeneities (e.g., precipitates) and lattice defects (e.g., dislocations and grain boundaries) [22]. Processing through SPD results in a large number of such lattice defects, which are potential corrosion sites. The predominant factor in the corrosion morphology of UFG Al-Mg alloys has been reported to be the dislocation density [23]. However, Bruner et al. [24] observed that the corrosion behavior of AA2024 UFG alloy processed through ECAP resulted in transformation of the corrosion mechanism from IGC to pitting corrosion via complete rearrangement of the grain boundaries, thereby revealing a desensitization effect. Improved corrosion resistance of UFG $\mathrm{Al}-4 \mathrm{Zn}-2 \mathrm{Mg}$ alloy produced by cryorolling has been attributed mainly to the absence of both (1) coarse deleterious $\mathrm{MgZn}_{2}$ precipitates and (2) the associated precipitate-free zones (PFZs) after aging [25]. Improvement in the pitting corrosion resistance of Al-Mg alloys processed by ECAP has been reported to be due to a decrease in the size of the impurity precipitates and an increase in the rate of formation of the Al oxide film on the surface [26]. The rate of forma- tion and the surface properties of the oxide film depend on the composition, which also determines the corrosion resistance of the alloy. The oxidation rate of $\mathrm{Al}$ also increases with increasing grain-boundary area and increasing dislocation density caused by SPD processes [26]. Hence, predicting the corrosion behavior of UFG $\mathrm{Al}$ alloys produced by SPD techniques is difficult.

In the present study, we investigated the effect of cryorolling on the aging behavior of AA2024 by comparing the aging curves of (1) solutionized, (2) cryorolled, and (3) room-temperature (RT)-rolled alloys aged at different temperatures. The tendency toward corrosion in an aqueous medium containing chloride ions was evaluated via the potentiodynamic polarization technique and electrochemical impedance spectroscopy (EIS). The propensity toward intergranular corrosion was studied using immersion in standard solutions. The main aim of the present work is to produce a UFG alloy through cryorolling and to investigate the effect of cryorolling on the corrosion behavior of AA2024 aluminum alloy by correlating its microstructural changes with its corrosion behavior.

\section{Materials and methods}

The material studied was AA2024-T3 in the form of 6.2-mm thick plates hereafter referred to as the as-received (AR) plates. The chemical composition (wt\%) of the alloy, as analyzed by inductively coupled plasma optical emission spectroscopy (ICP-OES), was $\mathrm{Al} 93.58, \mathrm{Cu} 4.233, \mathrm{Mg} 1.259$, Mn 0.481, Fe 0.157, Si 0.197, Ti 0.058, and V 0.006.

The samples were solutionized at $495^{\circ} \mathrm{C}$ in a CARBOLITE CWF 1300 furnace for $1 \mathrm{~h}$ followed by water quenching to obtain a supersaturated solid solution (SSSS). The first set of solutionized samples was soaked in liquid $\mathrm{N}_{2}$ for $10 \mathrm{~min}$ prior to cryorolling. The cryorolling was performed for a total reduction of $85 \%$ using a two-high rolling mill in multiple passes, resulting in a thickness reduction of $\sim 5 \%$ per pass to avoid adiabatic heating. The cryorolling samples were soaked in liquid $\mathrm{N}_{2}$ for at least $2 \mathrm{~min}$ after each pass. The second set of samples was subjected to RT rolling in a similar manner but without immersion in liquid $\mathrm{N}_{2}$. The third set of samples was subjected to direct aging without any rolling.

For corrosion testing, samples were drawn from the rolled strips; care was taken to avoid cracked edges. Microstructural characterization was carried out by optical microscopy (LEICA DM2500M), high-resolution transmission electron microscopy (HRTEM) (JEOL JEM-2200FS), and 
scanning electron microscopy (SEM) (FEI-430 NOVA NANO). For metallographic studies, the samples were etched with Keller's reagent $(2.5 \mathrm{~mL} \mathrm{HNO} 3,1.5 \mathrm{~mL} \mathrm{HCl}$, and $1 \mathrm{~mL} \mathrm{HF}$ in $95 \mathrm{~mL}$ of distilled water) to enable the grain boundaries in the microstructure to be clearly observed. The samples for TEM analysis were mechanically thinned to approximately $80 \mu \mathrm{m}$, cut into 3-mm-diameter discs using a punch, and polished using a twin-jet electropolisher (STRUERS TENUPOL-5) at $12 \mathrm{~V}$ and $-30^{\circ} \mathrm{C}$ (using liquid $\mathrm{N}_{2}$ ) until an electron transparent region appeared around the hole formed in the sample.

Artificial aging of (1) solutionized, (2) solutionized and cryorolled, and (3) solutionized and RT-rolled samples was carried out at 130,160 , and $190^{\circ} \mathrm{C}$ for approximately $24 \mathrm{~h}$ in a furnace maintained within $\pm 2^{\circ} \mathrm{C}$. The aging behavior was monitored by collecting samples for every $1 \mathrm{~h}$, measuring their hardness, and returning them to the furnace. Macrohardness was measured on a universal testing machine equipped with a Brinell probe with a 1.5 -mm-diameter tungsten carbide ball as the indenter; tests were carried out at a load of $200 \mathrm{~N}$. Microhardness measurements were carried out on a LEICA VMHT AUTO using a square-based diamond indenter at a load of $0.98 \mathrm{~N}$ and a dwell time of $15 \mathrm{~s}$.

Corrosion studies were performed using a computer-controlled potentiostat/galvanostat and the ACM V4 software package. A three-electrode setup consisting of a saturated calomel electrode ( $\mathrm{SCE}, \mathrm{Hg} / \mathrm{Hg}_{2} \mathrm{Cl}_{2}$ ) as the reference electrode (RE), graphite as the auxiliary/counter electrode (AE), and the samples as the working electrode (WE) was used. Potentiodynamic polarization studies were carried out with reference to the open-circuit potential (OCP) in the potential range of $-250 \mathrm{mV} \leq \mathrm{OCP} \leq+500$ $\mathrm{mV}$ at a scan rate of $100 \mathrm{mV} / \mathrm{min}$ in an aerated $3.5 \mathrm{wt} \%$ $\mathrm{NaCl}$ aqueous solution. EIS studies were also carried out over the frequency range from 0.01 to $10000 \mathrm{~Hz}$ at constant potential in a similar aerated $3.5 \mathrm{wt} \% \mathrm{NaCl}$ aqueous solution using a potential amplitude of $10 \mathrm{mV}$; the OCP was taken as the reference potential from the potentiodynamic study. IGC testing was carried out according to ASTM standard G110 - 2003 by immersing the samples for $24 \mathrm{~h}$ in the test solution. The solution for IGC testing was composed of $57 \mathrm{~g} \mathrm{NaCl}+10 \mathrm{~mL} \mathrm{H}_{2} \mathrm{O}_{2}$ in $1 \mathrm{~L}$ of distilled water. The IGC test samples were analyzed by SEM to evaluate the grain-boundary attack. All of the corrosion tests were carried out at least three times for each condition, and the mean value of the results was reported along with the standard deviation.

\section{Results and discussion}

\subsection{Microstructural analysis}

AA2024-T3 alloy in the AR condition was studied by optical microscopy and TEM to characterize its grain size and the size and nature of its constituent particles and precipitates. The grain-size from optical microscopy, as determined using the linear intercept method, was $(75 \pm 10)$ $\mu \mathrm{m}$, and coarse particles were observed in the micrographs, especially in the grain boundaries marked by arrows in Figs. 1(a) and 1(b). These coarse constituent particles in grain boundaries are the main cause of corrosion in $\mathrm{Al}$ alloys [18-22].

TEM micrographs of the AR alloy reveal the morphology and distribution of precipitates, as shown in Figs. 1(c) and $1(\mathrm{~d})$. The coarse grain-boundary precipitation was confirmed on the basis of Fig. 1(d). The TEM micrographs show needle-shaped precipitates $\left(\mathrm{Al}_{2} \mathrm{CuMg}\right)$ and rod-shaped particles $\left(\mathrm{Al}_{20} \mathrm{Cu}_{2} \mathrm{Mn}_{3}\right)$ in the matrix and aligned along the grain boundary, respectively [18-20]. The composition of the precipitates shown in Fig. 1(e) was confirmed to be $\mathrm{Al}_{2} \mathrm{CuMg}$ by the corresponding energy-dispersive spectroscopic (EDS) analysis results shown in Fig. 1(f). The rod-shaped $\mathrm{Al}_{20} \mathrm{Cu}_{2} \mathrm{Mn}_{3}$ particles are remnant T-phase particles, which aid in trapping high concentrations of dislocation densities and also act as potential sites for the production of dislocations during subsequent deformation [15]. Most of the particles in the AR material exhibited this rod-shaped morphology, with a maximum size of $\sim 1.5 \mu \mathrm{m}$. The optical micrographs of both the cryorolled and RT-rolled samples prior to aging, which are shown in Figs. 2(a) and 2(b), did not reveal any grain structure because of the heavy deformation (rolling). The rolling direction (RD) is indicated by arrows, and the alignment of fragmented coarse constituent particles along the RD was observed.

Aging of the solutionized, cryorolled, and RT-rolled samples was carried out at 130,160 , and $190^{\circ} \mathrm{C}$ to investigate the effect of temperature on the aging characteristics of the samples. The optical micrographs of the cryorolled and aged alloy samples did not reveal any coarse grain structure or coarse grain-boundary precipitates, even after aging, as shown in Figs. 3(a) and 3(b) [27], indicating the formation of a UFG structure. However, optical micrographs of the solutionized and peak aged (CGPA) alloy (aged at $160^{\circ} \mathrm{C}$ for $24 \mathrm{~h}$ ) revealed coarse grain-boundary precipitation, as shown in Figs. 4(a) and 4(b), with a peak hardness of $\mathrm{HV}_{0.1}$ 155. The coarse precipitation along the grain boundaries creates precipitate-free zones (PFZs) adjacent to the grain 
boundaries, leading to a potential difference between PFZs and precipitates leading to IGC.

\subsection{Age-hardening behavior}

The results in Table 1 indicate that the cryorolled alloy exhibited relatively high hardness compared with the
RT-rolled alloy because of its high dislocation density, which resulted from arresting the dynamic recovery at cryogenic temperatures during cryorolling [28]. By contrast, RT-rolled samples exhibited lower hardness because of adiabatic heating, which results in annihilation of the dislocations during deformation [29].
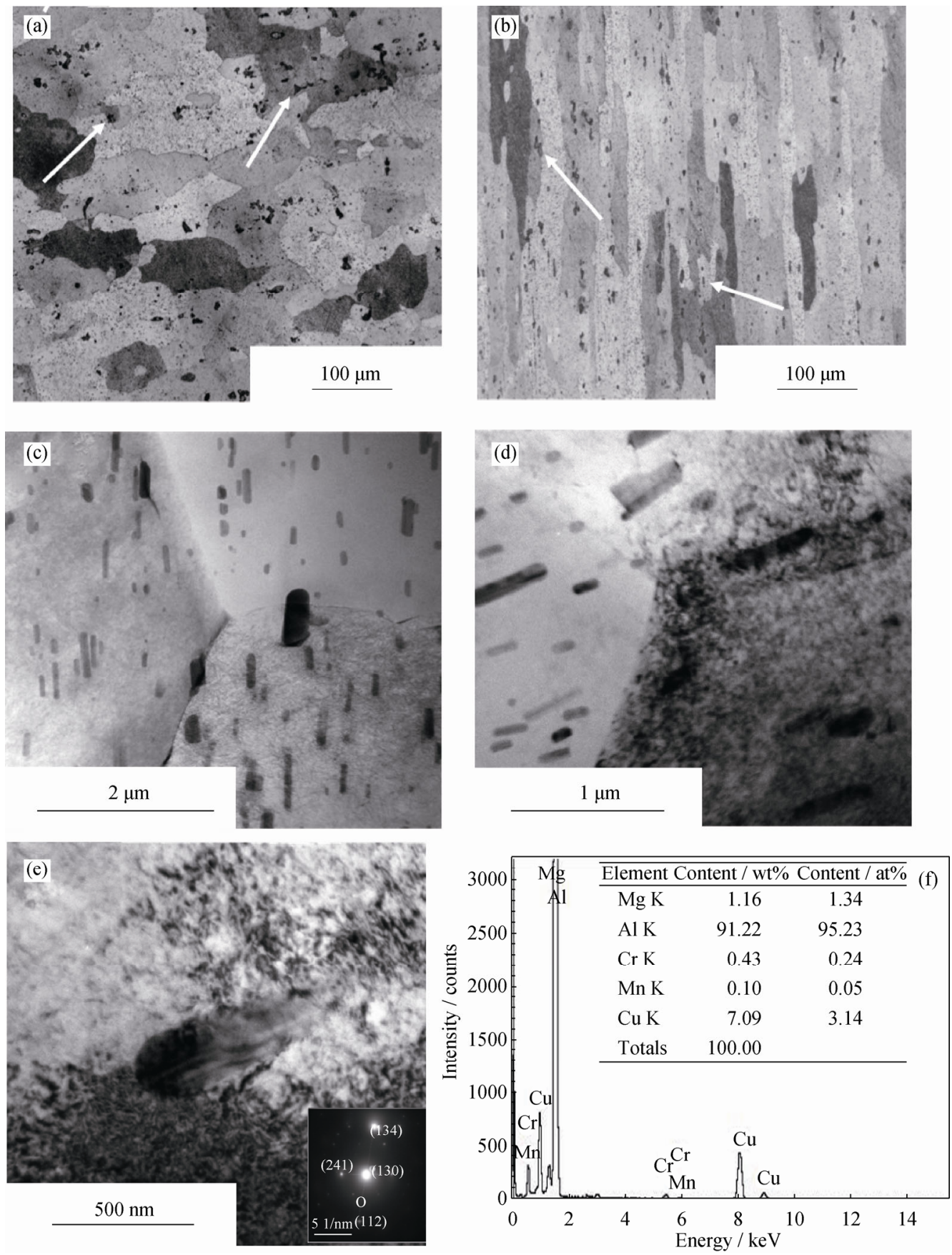

Fig. 1. Optical micrographs of AA2024 AR: (a) surface and (b) transverse cross section (etchant: Keller's); TEM micrographs of AA2024 AR revealing: (c) a grain-boundary triple point, (d) precipitates aligned along the grain boundary, and (e) $\mathrm{Al}_{2} \mathrm{CuMg}$ precipitates (the corresponding selected-area diffraction pattern (SADP) is shown in the inset); (f) EDS analysis results for the precipitate observed in subfigure (e). 

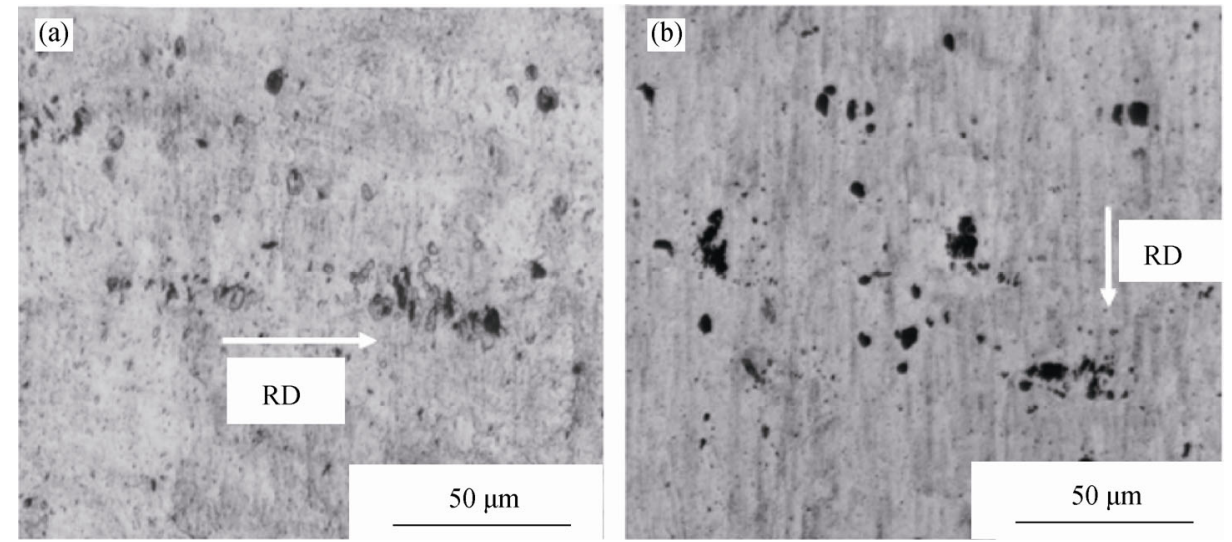

Fig. 2. Optical micrographs of (a) cryorolled and (b) room-temperature (RT)-rolled AA2024 aluminum alloy samples (etchant: Keller's).
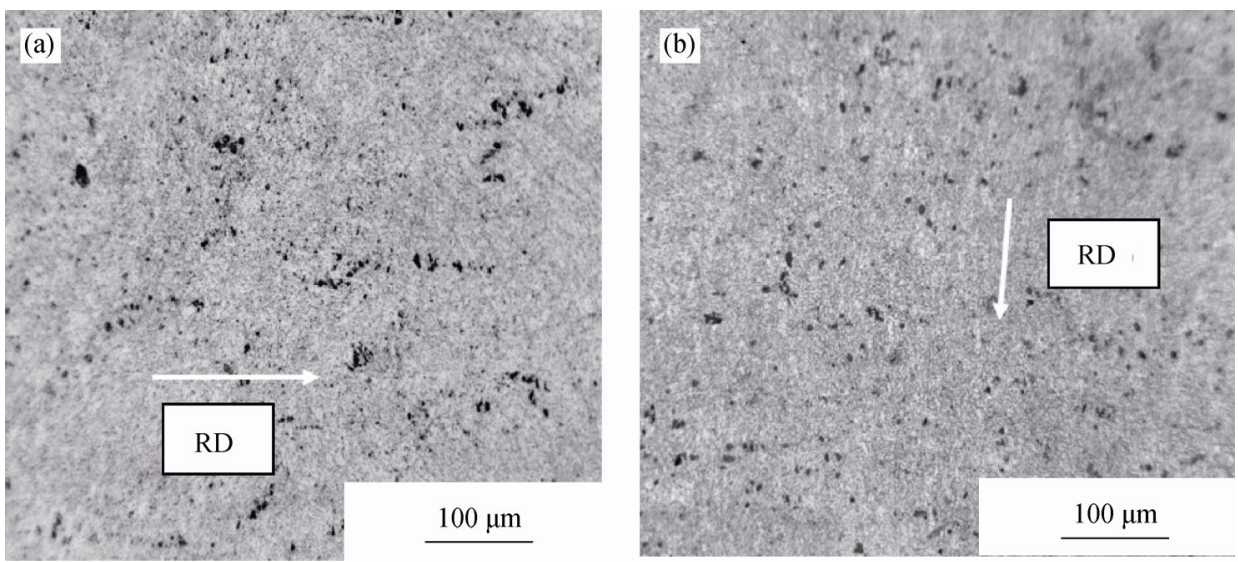

Fig. 3. Optical micrographs of AA2024 aluminum alloy samples cryorolled and aged at $160^{\circ} \mathrm{C}(\mathrm{CRPA})$ (a) and RT-rolled and aged at $160^{\circ} \mathrm{C}$ (b) (etchant: Keller's).
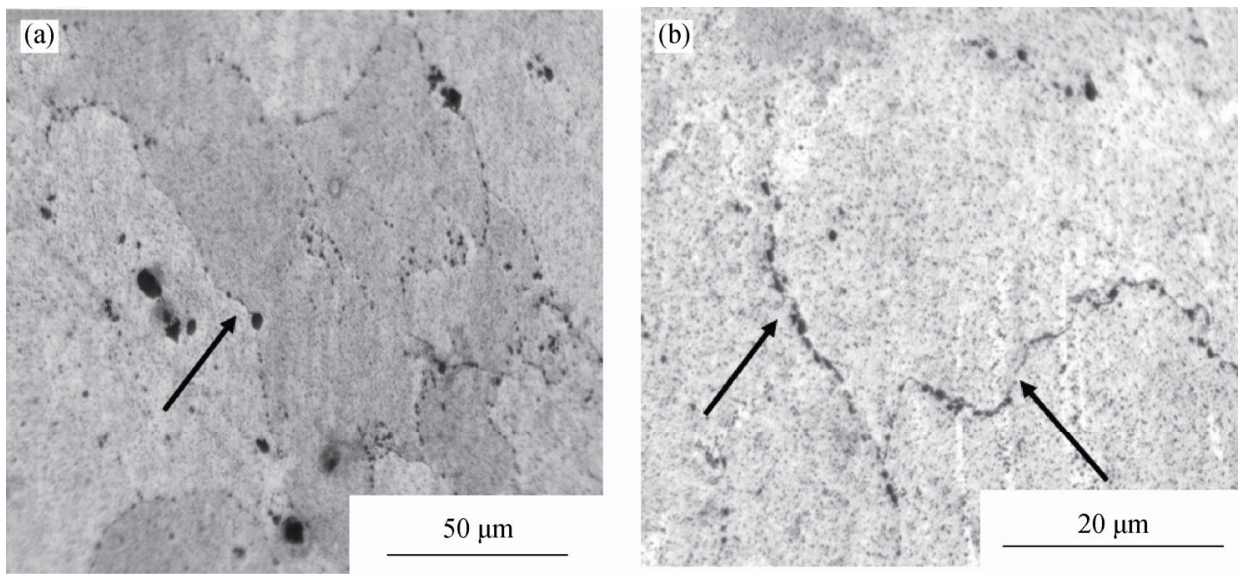

Fig. 4. Optical micrographs of the AA2024 aluminum alloy solutionized and aged at $160^{\circ} \mathrm{C}$ (CGPA) at different magnifications (etchant: Keller's).

Table 1. Results of Brinell hardness (BHN) measurements at a load of $210 \mathrm{~N}$

\begin{tabular}{|c|c|c|c|c|}
\hline Sample-condition & $\begin{array}{c}\text { As-received (AR) } \\
\text { (6.2 mm in thickness) } \\
\text { [equivalent HV] }\end{array}$ & $\begin{array}{c}\text { Solutionized } \\
\text { (6.2 mm in thickness) } \\
\text { [equivalent HV] }\end{array}$ & $\begin{array}{c}\text { Cryorolled } \\
(0.9 \mathrm{~mm} \text { in thickness and } \\
85 \% \text { reduction }) \\
\text { [equivalent } \mathrm{HV}]\end{array}$ & $\begin{array}{c}\text { RT-rolled } \\
\text { (0.9 mm in thickness and } \\
85 \% \text { reduction }) \\
\text { [equivalent } \mathrm{HV}]\end{array}$ \\
\hline AA2024-T3 & $\begin{array}{c}123 \pm 2 \\
{[157]}\end{array}$ & $\begin{array}{c}96 \pm 2 \\
{[123]}\end{array}$ & $\begin{array}{c}186 \pm 2 \\
{[215]}\end{array}$ & $\begin{array}{c}166 \pm 2 \\
{[196]}\end{array}$ \\
\hline
\end{tabular}


The cryorolled and RT-rolled alloys aged at 130, 160, and $190^{\circ} \mathrm{C}$ exhibited different hardness profiles indicating under-aging, peak aging, and over-aging, respectively, of the alloy [15]. During aging at $190^{\circ} \mathrm{C}$, the hardness for both the cryo- and RT-rolled samples continuously decreased, as shown in Fig. 5(a), because of recovery and recrystallization. The recrystallization temperature is well known to decrease with increasing heavy cold work, and the hardness of materials decreases during recrystallization as new strain-free crystals are formed. Both the cryo- and RT-rolled samples show similar patterns of decreasing hardness, the onset of recrystallization occurs immediately at $190^{\circ} \mathrm{C}$ because of heavy cold work and also because the low-angle grain boundaries formed during cryorolling provide many nucleation sites for recrystallization [30-32]. As detailed in Table
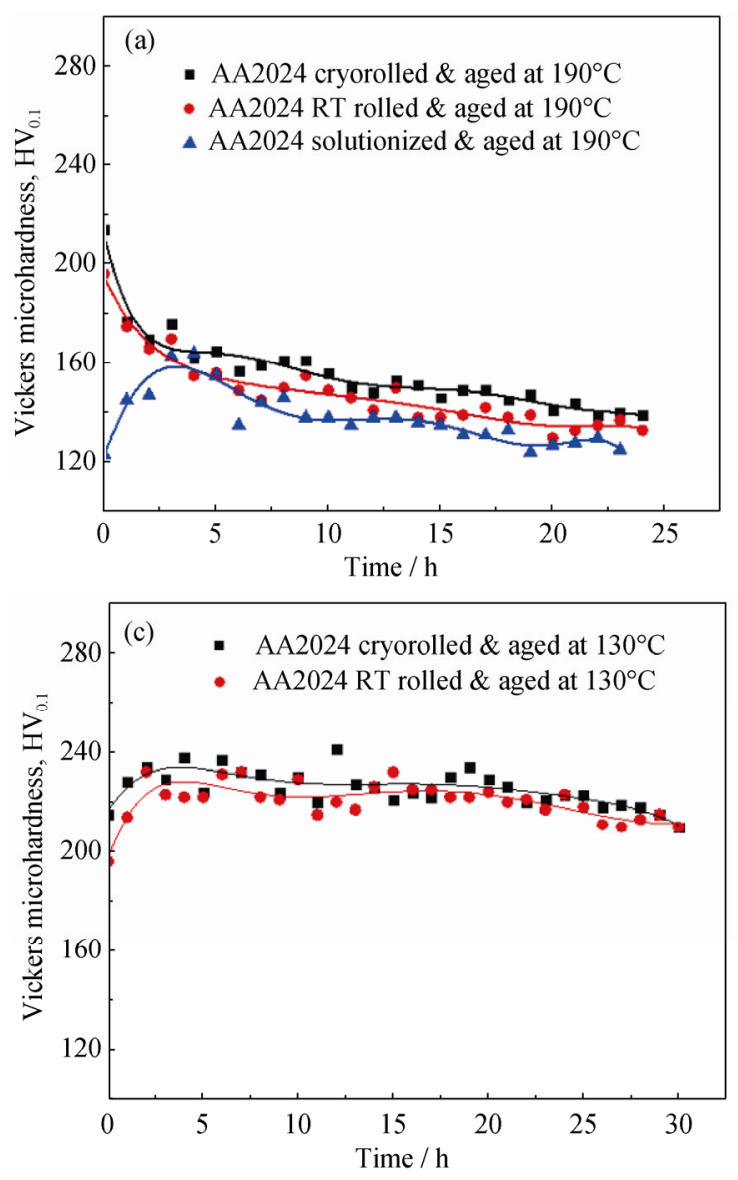

Aging of the cryo- and RT-rolled samples at $160^{\circ} \mathrm{C}$ resulted in peak hardness (Fig. 5(b)) in the first hour of aging itself; the subsequent decrease is likely attributable to coarsening of precipitates. The cryorolled sample showed a peak hardness of $\mathrm{HV}_{0.1}$ 230, whereas the RT-rolled sample showed a peak hardness of $\mathrm{HV}_{0.1} 213$ in the first hour of aging, as illustrated in Table 2. The solutionized sample
2, the peak hardness in the total profile of the sample aged at $190^{\circ} \mathrm{C}$ is $\mathrm{HV}_{0.1} 176$ for the cryorolled sample and $\mathrm{HV}_{0.1} 169$ for the RT-rolled sample with $3 \mathrm{~h}$ of aging, which reveals that the severely deformed alloys exhibit accelerated aging kinetics. The aging of the solutionized sample at $190^{\circ} \mathrm{C}$ shows an increase in hardness, which is attributable to rapid hardening induced by the formation of fine-scale solute clusters comprising $\mathrm{Cu}$ and $\mathrm{Mg}$ but with minor concentrations of $\mathrm{Si}$ and $\mathrm{Zn}$ [4]; the regions where the clusters form are called Guinier-Preston-Bagaryatsky (GPB) zones. The solutionized sample aged at $190^{\circ} \mathrm{C}$ exhibited a peak hardness of $\mathrm{HV}_{0.1} 164$ after $5 \mathrm{~h}$ of aging, as shown in Fig. 5(a), because of the precipitation of the $\mathrm{S}$ phase $\left(\mathrm{Al}_{2} \mathrm{CuMg}\right)$; the subsequent decrease in hardness of this sample was due to the coarsening of these precipitates [33].

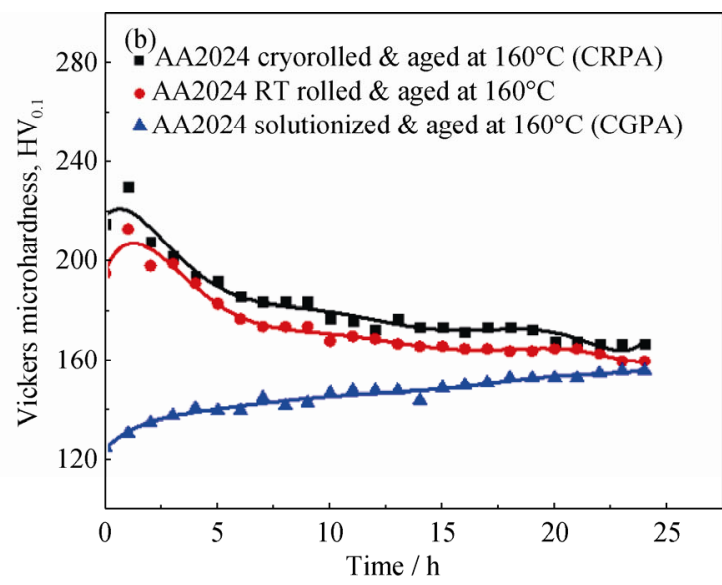

Fig. 5. Artificial aging of cryorolled, RT-rolled, and solutionized AA2024 aluminum alloy samples aged at different temperatures: (a) $190^{\circ} \mathrm{C}$; (b) $160^{\circ} \mathrm{C}$; (c) $130^{\circ} \mathrm{C}$. showed a continuous increase in hardness during $24 \mathrm{~h}$ of aging at $160^{\circ} \mathrm{C}$, and the peak hardness reached $\mathrm{HV}_{0.1} 155$. This result shows that the peak aging time was decreased to $1 \mathrm{~h}$ after severe deformation [34]. SPD alloys show accelerated aging kinetics because the large number of dislocations provides many nucleation sites for the precipitation of fine particles [35]. 
Table 2. Peak hardness at different aging temperatures of AA2024 aluminum alloy samples

\begin{tabular}{lccc}
\hline \multirow{2}{*}{ Sample } & \multicolumn{3}{c}{ Peak hardness $\left(\mathrm{HV}_{0.1}\right) /$ Aging time $(\mathrm{h})$} \\
\cline { 2 - 4 } & $\begin{array}{c}\text { Aging at } \\
130^{\circ} \mathrm{C}\end{array}$ & $\begin{array}{c}\text { Aging at } \\
160^{\circ} \mathrm{C}\end{array}$ & $\begin{array}{c}\text { Aging at } \\
190^{\circ} \mathrm{C}\end{array}$ \\
\hline Solutionized & - & $155 \pm 2 / 24 \mathrm{~h}$ & $164 \pm 1 / 5 \mathrm{~h}$ \\
Cryorolled & $241 \pm 2 / 12 \mathrm{~h}$ & $230 \pm 5 / 1 \mathrm{~h}$ & $176 \pm 2 / 3 \mathrm{~h}$ \\
RT-rolled & $232 \pm 2 / 15 \mathrm{~h}$ & $213 \pm 5 / 1 \mathrm{~h}$ & $169 \pm 1 / 3 \mathrm{~h}$ \\
\hline
\end{tabular}

Both the cryorolled and RT-rolled alloy samples exhibited similar trends during aging at $130^{\circ} \mathrm{C}$, as shown in Fig. 5(c), because the aging temperature was too low to cause a large variation in their microstructures and because the hardness is relatively stable throughout the profile, confirming that $130^{\circ} \mathrm{C}$ was an under-aging temperature [33]. The peak hardness in the total profile was observed at $\mathrm{HV}_{0.1} 241$ for the sample cryorolled after $12 \mathrm{~h}$ of aging, whereas a hardness of $\mathrm{HV}_{0.1} 232$ for the RT-rolled sample after $15 \mathrm{~h}$ of
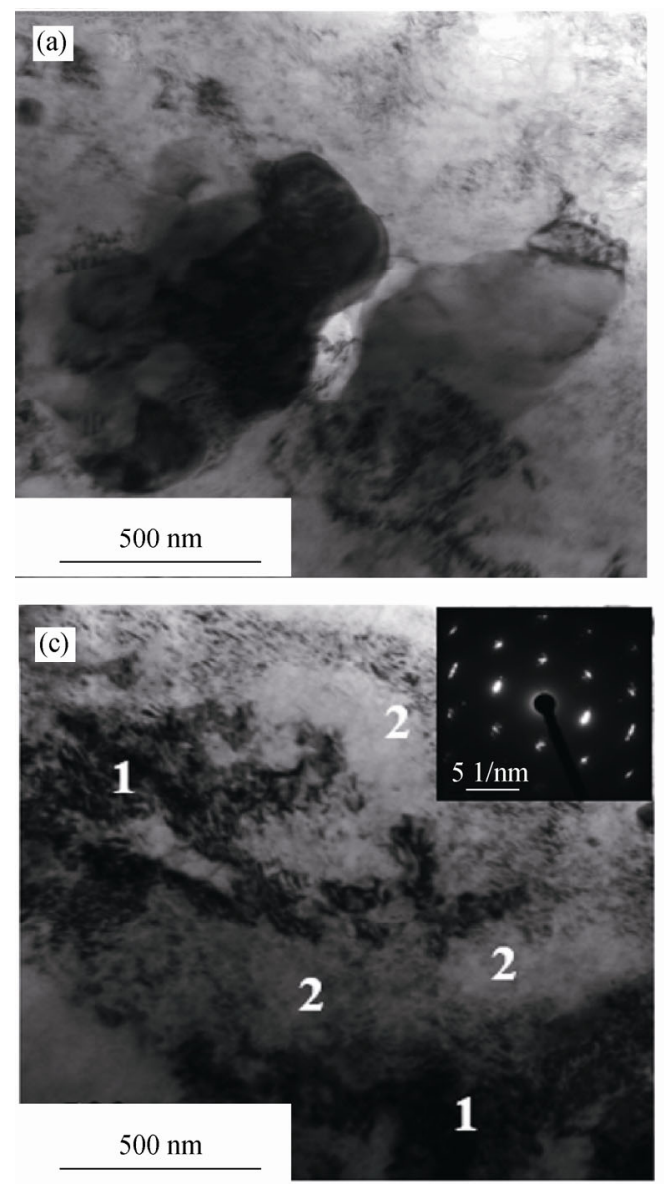

aging. This peak hardness is high in comparison with the values for the samples aged at either 160 or $190^{\circ} \mathrm{C}$ and is attributed to the formation of fine recrystallized grains and a large number of fine strengthening precipitates $\left(\mathrm{Al}_{2} \mathrm{CuMg}\right)$ [36]. The incomplete recovery results in lower ductility for the rolled alloys. The TEM images of the cryorolled samples aged at $130^{\circ} \mathrm{C}$ are shown in Fig. 6. Fig. 6(a) shows two recrystallized grains with a grain size of $\sim 1 \mu \mathrm{m}$, revealing the formation of UFG after the cryorolling and aging process. The precipitate observed in Fig. 6(b) is $\mathrm{Al}_{2} \mathrm{CuMg}$ with a size of $82 \mathrm{~nm}$ after aging. Fig. 6(c) shows the bimodal structure of grains after the sample was aged at $130^{\circ} \mathrm{C}$ for $30 \mathrm{~h}$; it also shows recrystallized and unrecrystallized zones labeled as 2 and 1, respectively [15]. Also, the selected-area diffraction pattern (SADP) in the inset shows a ring pattern that indicates the formation of ultrafine grains after cryorolling. Fig. 6(d) shows a single recrystallized grain of $1.5 \mu \mathrm{m}$ after aging. The average size of the precipitates formed after cryorolling and aging at $130^{\circ} \mathrm{C}$ for $30 \mathrm{~h}$ is $80-120 \mathrm{~nm}$ in this alloy.
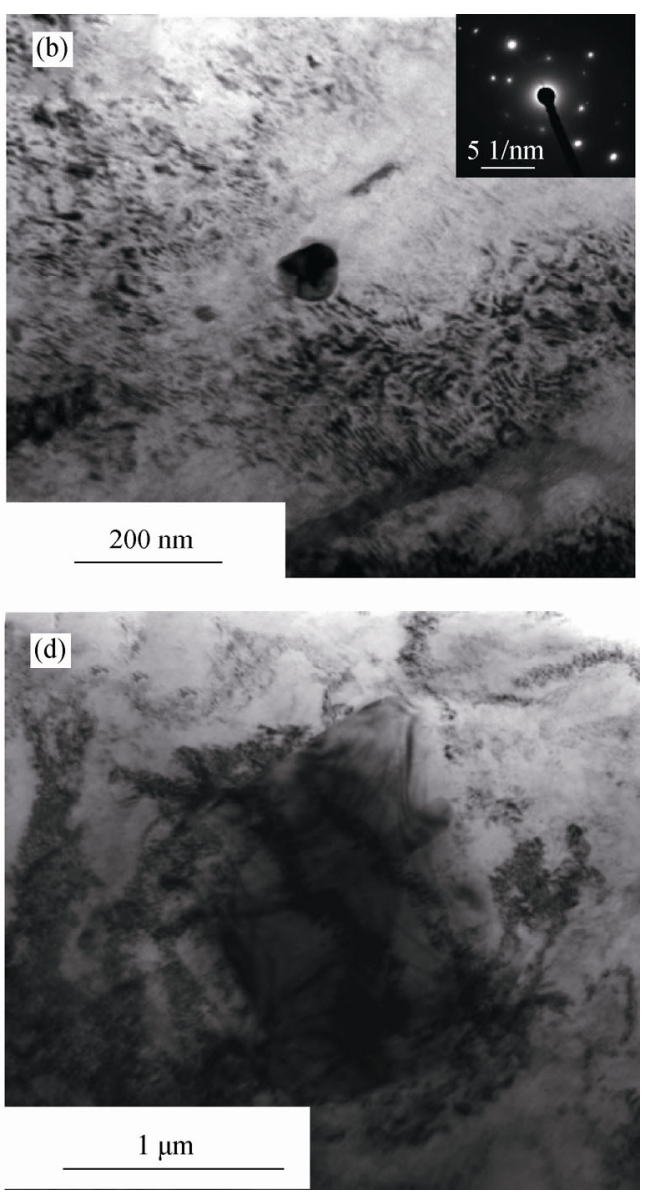

Fig. 6. Bright-field TEM micrographs of the AA2024 aluminum alloy cryorolled and aged at $130^{\circ} \mathrm{C}$, showing (a) recrystallized grains, (b) an $\mathrm{Al}_{2} \mathrm{CuMg}$ particle of $82 \mathrm{~nm}$ (inset: corresponding SADP), (c) the bimodal structure of grains, i.e., 1-unrecrystallized zone and 2-recrystallized zone (inset: corresponding SAD pattern), and (d) a single recrystallized grain. 


\subsection{Potentiodynamic polarization}

Potentiodynamic polarization studies were carried out for the AR alloy and the solutionized and cryorolled alloys, and their respective thermodynamic and kinetic parameters, including their corrosion potential $\left(E_{\text {corr }}\right)$ and corrosion current density $\left(i_{\text {corr }}\right)$, are reported. The polarization curve of the cryorolled alloy, as shown in Fig. 7, is shifted toward more negative potentials than the curve of the solutionized alloy, indicating more reduction reactions are occurring on the sample surface of the cryorolled alloy and that these reactions are under cathodic control [37].

The corrosion current density $\left(i_{\text {corr }}\right)$ values obtained by the Tafel extrapolation method are given in Table 3 . These values reveal that the cryorolled alloy $((1.1852 \pm 0.2)$ $\left.\mu \mathrm{A} / \mathrm{cm}^{2}\right)$ exhibited a higher $i_{\text {corr }}$ than the AR alloy $((1.0729 \pm$ $0.2) \mu \mathrm{A} / \mathrm{cm}^{2}$ ), reflecting that the rate of corrosion increased in the case of the cryorolled alloy. The inferior corrosion properties of the as-cryorolled alloy compared with those of the solutionized alloy are attributable to structural defects such as a large number of dislocations and a high-grain-boundary area formed during deformation. Sivaprasad et al. [38] have reported similar observations, where commercial pure $\mathrm{Al}$ rolled at $-80^{\circ} \mathrm{C}$ exhibited inferior corrosion resistance compared with pure $\mathrm{Al}$ in the solutionized condition.

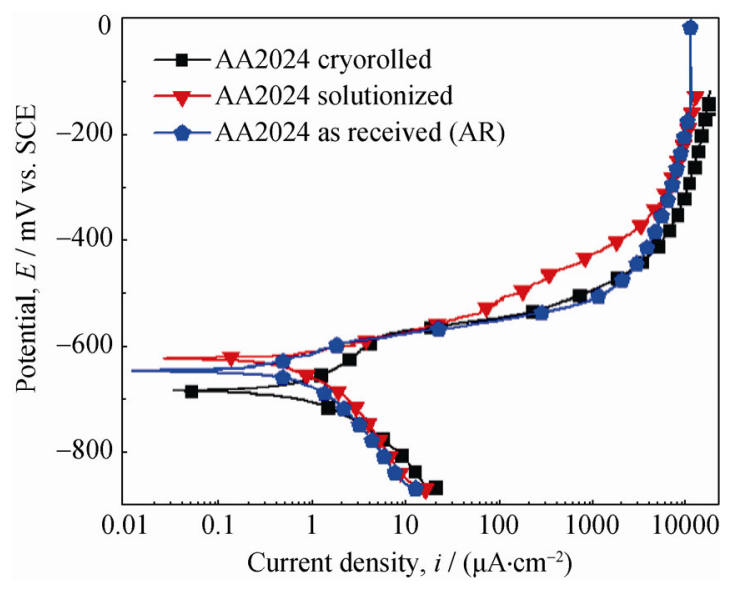

Fig. 7. Potentiodynamic polarization curves of as received, solutionized, and cryorolled AA2024 aluminum alloy samples in $3.5 \mathrm{wt} \% \mathrm{NaCl}$ aqueous solution.

Table 3. Corrosion potentials and current densities of AR, solutionized, and rolled AA2024 aluminum alloy samples

\begin{tabular}{lccc}
\hline \multicolumn{1}{c}{ Sample } & $E_{\text {corr }} / \mathrm{mV}$ vs. SCE & $i_{\text {corr }} /\left(\mu \mathrm{A} \cdot \mathrm{cm}^{-2}\right)$ & ${\text { Corrosion rate } / \mathrm{mpy}^{*}}^{*}$ \\
\hline As-received (AR) & $-648.79 \pm 5$ & $1.0729 \pm 0.2$ & 0.465 \\
Solutionized & $-628.12 \pm 5$ & $0.9451 \pm 0.1$ & 0.410 \\
Cryorolled & $-676.34 \pm 6$ & $1.1852 \pm 0.2$ & 0.514 \\
Cryorolled and aged at $160^{\circ} \mathrm{C}(\mathrm{CRPA})$ & $-673.60 \pm 4$ & $0.3809 \pm 0.1$ & 0.165 \\
Solutionized and aged at $160^{\circ} \mathrm{C}(\mathrm{CGPA})$ & $-696.14 \pm 6$ & $1.5079 \pm 0.4$ & 0.653 \\
Cryorolled and aged at $190^{\circ} \mathrm{C}$ & $-712.11 \pm 4$ & $0.6643 \pm 0.1$ & 0.287 \\
Solutionized \& aged at $190^{\circ} \mathrm{C}$ & $-714.81 \pm 6$ & $3.8635 \pm 0.3$ & 1.674 \\
\hline
\end{tabular}

Note: mpy means mils per year.

The (1) as-solutionized and (2) solutionized and cryorolled alloys uniformly and artificially aged at $160^{\circ} \mathrm{C}$ for 24 $\mathrm{h}$ are designated as CGPA and CRPA, respectively. Potentiodynamic polarization studies were carried out to investigate the feasibility of particle-induced corrosion. No significant variation in OCP was observed in the case of the CRPA alloy, as shown in Fig. 8, indicating the absence of dissolution of the constituent particles in the initial stages of corrosion [37]. Fig. 9 shows that the $E_{\text {corr }}$ of the CRPA alloy $(-673.6 \mathrm{mV})$ was shifted toward more positive potentials compared with that of the CGPA alloy $(-696.14 \mathrm{mV})$, indicating a lower thermodynamic tendency of the CRPA alloy toward the electrochemical reactions. However, the solutionized sample exhibits a more positive $E_{\text {corr }}(-628.11 \mathrm{mV})$ because it exhibits a lesser thermodynamic tendency toward electrochemical reactions than the CRPA alloy because of complete dissolution of alloying elements, including $\mathrm{Cu}$, which shifted the super saturated solid solution toward more positive potentials in the solutionized state.

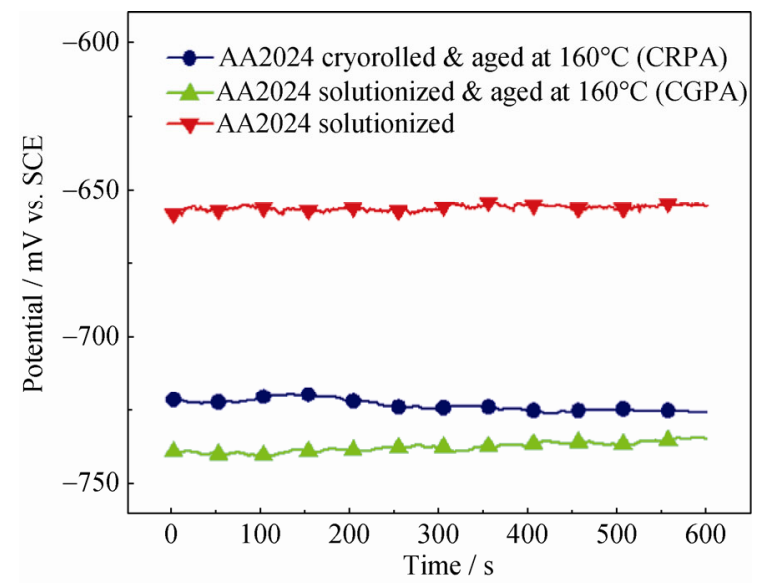

Fig. 8. Open-circuit potential (OCP) of solutionized, CRPA, and CGPA AA2024 aluminum alloy samples in $3.5 \mathrm{wt} \% \mathrm{NaCl}$ aqueous solution. 


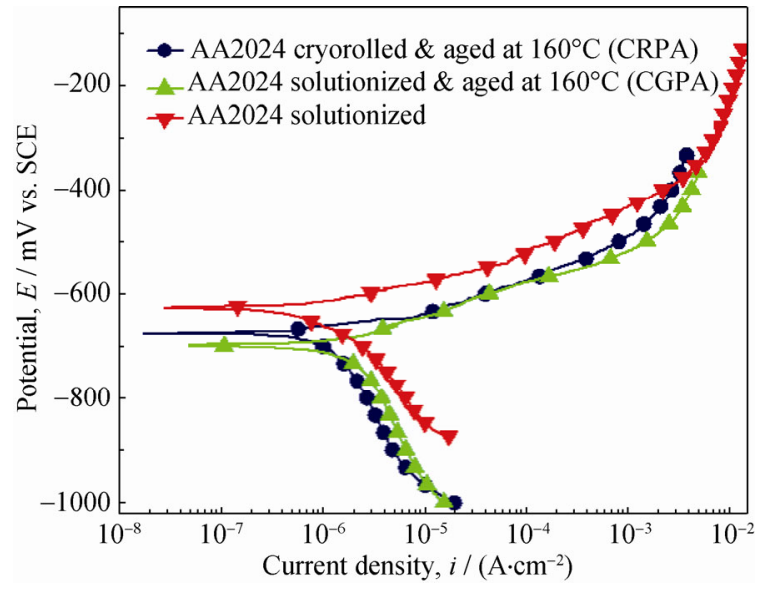

Fig. 9. Potentiodynamic polarization curves of solutionized, CRPA, and CGPA AA2024 aluminum alloy samples in 3.5wt\% $\mathrm{NaCl}$ aqueous solution.

A substantial decrease in the $i_{\text {corr }}\left((0.3809 \pm 0.1) \mu \mathrm{A} / \mathrm{cm}^{2}\right)$ value was observed in the case of the CRPA alloy, which reflects its low corrosion rate (CR), as evident from the results in Table 3. Thus, the CRPA alloy showed substantially improved corrosion properties comparison with the CGPA alloy. However, the sample cryorolled and aged at $190^{\circ} \mathrm{C}$ showed an $i_{\text {corr }}\left((0.6643 \pm 0.1) \mu \mathrm{A} / \mathrm{cm}^{2}\right)$ value greater than that of the CRPA alloy. This high $i_{\text {corr }}$ value is attributed to over-aging; i.e., it is attributed to the coalescence of fine precipitates into coarser precipitates fewer in number and concentrating only

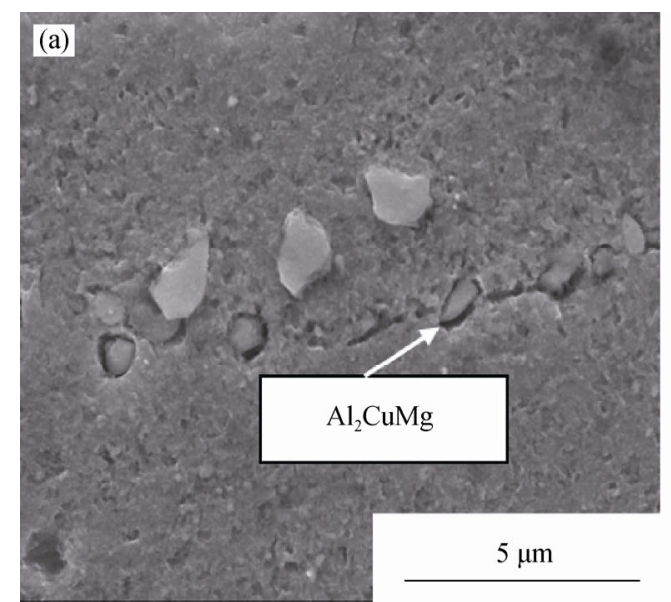

in some portions of the alloy, thereby a creating nonuniform distribution and PFZs. Devaiah et al. have reported similar observations, where a cryorolled sample aged at $190^{\circ} \mathrm{C}$ showed coarse grains and agglomeration of precipitates [15].

The improved corrosion resistance of the CRPA alloy is related to its fine grains and to the formation of fine strengthening precipitates uniformly distributed throughout the alloy, thereby avoiding the formation of PFZs [20]. The higher corrosion rate of the CGPA alloy was due to its coarse grain-boundary precipitates, as shown in the SEM image in Fig. 10(a). EDS analysis confirmed that the coarse grain-boundary segregates are S-phase $\left(\mathrm{Al}_{2} \mathrm{CuMg}\right)$ anodic precipitates, which will preferentially dissolve from the matrix in a corrosive medium [18], as shown in Fig. 10(b). These S-phase precipitates are potential corrosion sites that, through the creation of PFZs, are nonuniformly distributed along the grain boundaries, leading to higher corrosion rates in the solutionized and aged alloys. Krishna et al. [25] investigated the effect of microstructure on the corrosion behavior of an UFG Al-4Zn-2Mg alloy produced by cryorolling and reported that the cryorolled alloy subjected to peak aging exhibited improved corrosion resistance compared to the coarse-grained peak-aged sample. They attributed this increased resistance to submicrometer grains, the absence of coarse $\mathrm{MgZn}_{2}$ anodic precipitates, and the formation of PFZs along the grain boundaries [25].

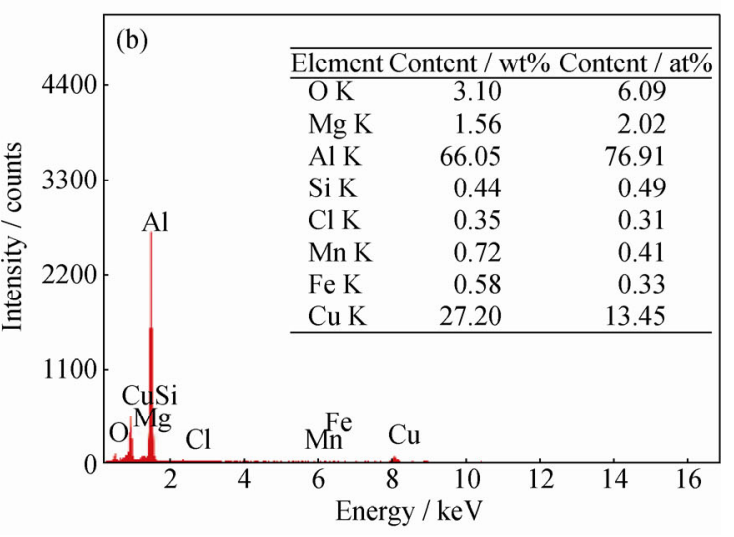

Fig. 10. (a) SEM secondary electron image of the AA2024 aluminum alloy sample solutionized and aged at $190^{\circ} \mathrm{C}$; (b) corresponding EDS analysis of the grain-boundary precipitate marked by the arrow in (a).

\subsection{Electrochemical impedance spectroscopy}

EIS has been popularly used in the field of corrosion as a powerful method to study the surface condition of metals in aggressive environments [39]. It can be used to characterize, in terms of electrical measurements, a chemical process occurring at the electrode/electrolyte interface. EIS gives information about the response of a circuit to an alternating current $(I)$ or voltage $(V)$ as a function of frequency $(f)$. Nyquist plots are frequency-independent, providing information about the charge transfer resistance $\left(R_{\mathrm{ct}}\right)$ and the solution resistance $\left(R_{\mathrm{S}}\right)$ in a corrosive medium. The inhibition of charge transfer is represented by $R_{\mathrm{ct}}$. The compact native oxide layer on the surface retards the transport of corrosive ions to interact with the substrate. The charge transfer process 
occurs only at the electrode-electrolyte interface [39].

The Nyquist plots (Fig. 11) of the CRPA and CGPA exhibit two capacitive loops, which are also reflected in the Bode impedance plots in Fig. 12, revealing the formation of two complex oxide layers on the surface in the chloride solution environment. The corrosion process of the cryorolled alloy can be explained on the basis of the equivalent circuits shown in Fig. 13(a); the experimental EIS results were translated to the equivalent circuit models using the ZSimpWin ${ }^{\circledR}$ software.

In the equivalent circuits, the capacitance is replaced by a constant phase element (CPE, impure capacitance) because of dispersion effects induced by the microscopic roughness of the sample surface. The CPE impedance is related as

$Z_{\mathrm{CPE}}=\frac{1}{Y_{\mathrm{o}}(\mathrm{j} \omega)^{n}}$

where $\omega$ is the angular frequency $(\mathrm{rad} / \mathrm{s}), \mathrm{j}$ is the imaginary constant, $Y_{\mathrm{o}}$ and $n$ are frequency-independent parameters [40]. In the case of nonuniform corrosion models, the $R_{\mathrm{ct}}$ can be correlated to the $\mathrm{CR}$ rather than to the polarization resistance $\left(R_{\mathrm{p}}\right)$ by the faradaic process of a charge-transfer-controlled corrosion mechanism [41]. As evident from the fitting parameters of the equivalent circuit in Fig. 13(b), the $n_{1}$ value for the CRPA alloy (Table 4) is approximately 1, indicating the pure capacitance of the outer passive oxide layer. The outer oxide layer of the CGPA alloy is completely covered by corrosion products $\left(\mathrm{AlOHCl}, \mathrm{AlOHCl}_{2}\right)$, as revealed by its higher capacitance $\left(Y_{\mathrm{o} 1}=5.65 \times 10^{-5} \mathrm{~S} /\left(\mathrm{cm}^{2} \cdot \mathrm{s}^{n}\right)\right)$ from Table 4. However, the greater volume fraction of the stable inner oxide film for the CRPA alloy retards the migration of $\mathrm{Cl}^{-}$ ions and corrosion products, which leads to an increase in charge transfer resistance $\left(9810 \Omega \cdot \mathrm{cm}^{2}\right)$ and promotes the re-passivation of metastable pits as compared to the CGPA alloy. In the Nyquist plot, the inner oxide layer for the CRPA alloy resulted in a full capacitance loop that is close to the ideal curve. The Warburg impedance $(W)$ conveys the mass transfer resistance, i.e., the resistance to the diffusion of ionic species near the inner oxide film. The Warburg impedance is relatively high for the CRPA $\left(1.898 \times 10^{9} \Omega \cdot \mathrm{s}^{0.5}\right)$ alloy compared with that for the CGPA alloy $\left(6.925 \times 10^{4}\right.$ $\Omega \cdot \mathrm{s}^{0.5}$ ) alloy, revealing an improvement in the properties of the oxide layer formed after cryorolling and aging.

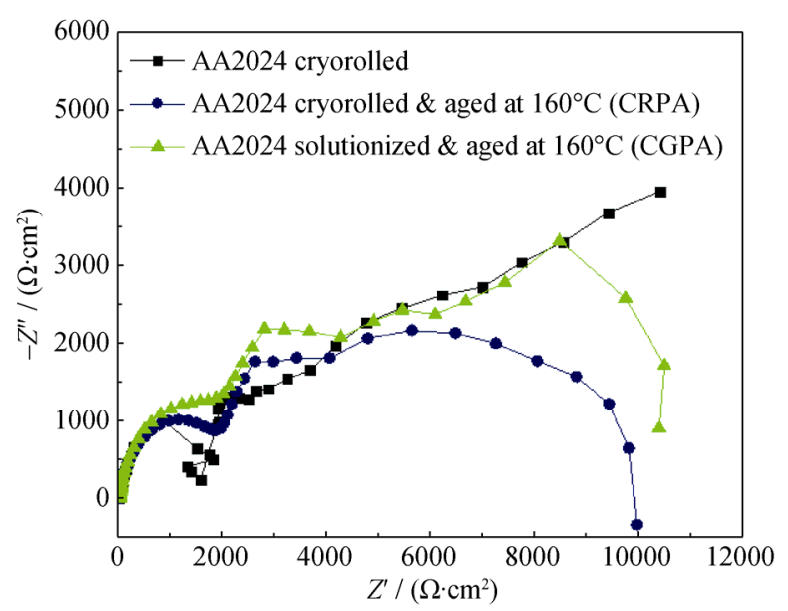

Fig. 11. Nyquist plots of cryorolled, CRPA, and CGPA AA2024 aluminum alloy samples in $3.5 \mathrm{wt} \% \mathrm{NaCl}$ aqueous solution.

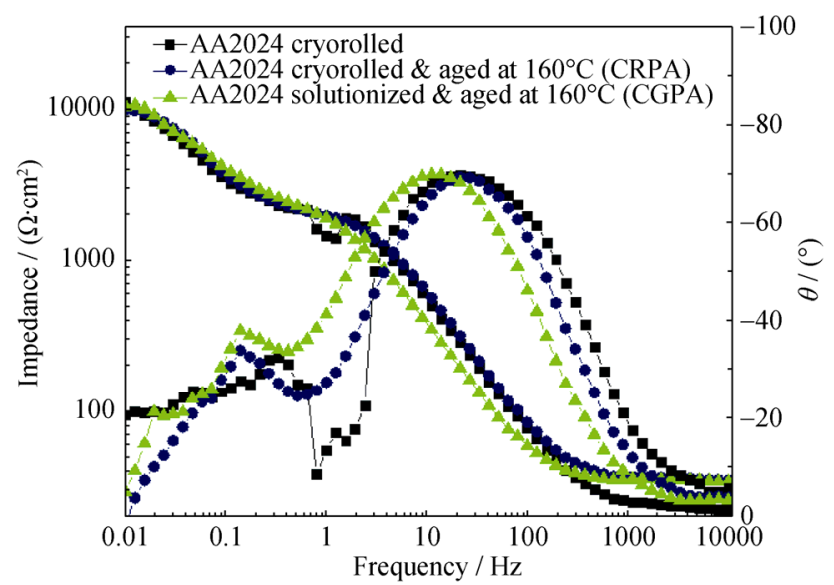

Fig. 12. Bode impedance and phase-angle plots of cryorolled, CRPA, and CGPA AA2024 aluminum alloy samples in $3.5 \mathrm{wt} \%$ $\mathrm{NaCl}$ aqueous solution.
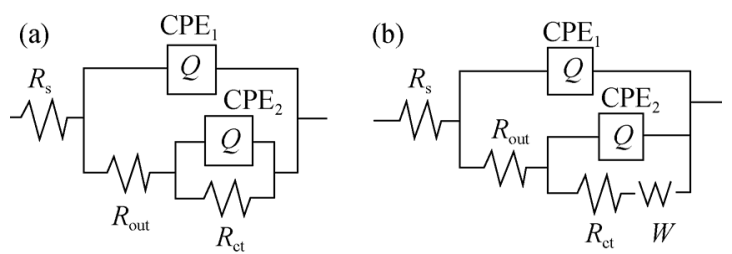

Fig. 13. Equivalent circuits of (a) cryorolled and (b) CRPA and CGPA alloys, where $R_{\mathrm{s}}$ is the solution resistance, $Q$ represents constant phase element (CPE), $\mathrm{CPE}_{1}$ is the outer-layer capacitance including the passive film corrosion products, $R_{\text {out }}$ is the resistance of the corrosion product, $\mathrm{CPE}_{2}$ is the double-layer capacitance, $R_{\mathrm{ct}}$ is the charge transfer resistance, and $W$ is the Warburg impedance.

Table 4. EIS fitting parameters of AA2024 aluminum alloy samples subjected to different treatments

\begin{tabular}{|c|c|c|c|c|c|c|c|c|}
\hline Sample & $R_{\mathrm{S}} /\left(\Omega \cdot \mathrm{cm}^{2}\right)$ & $Y_{\mathrm{o} 1} /\left(\mathrm{S} \cdot \mathrm{cm}^{-2} \cdot \mathrm{s}^{-n}\right)$ & $n_{1}$ & $R_{\text {out }} /\left(\Omega \cdot \mathrm{cm}^{2}\right)$ & $Y_{\mathrm{o} 2} /\left(\mathrm{S} \cdot \mathrm{cm}^{-2} \cdot \mathrm{s}^{-n}\right)$ & $n_{2}$ & $R_{\mathrm{ct}} /\left(\Omega \cdot \mathrm{cm}^{2}\right)$ & $W /\left(\Omega \cdot \mathrm{s}^{0.5}\right)$ \\
\hline Cryorolled & 34.67 & $2.50 \times 10^{-5}$ & 0.8 & 1159 & $2.90 \times 10^{-4}$ & 0.5 & 8210 & - \\
\hline $\begin{array}{l}\text { Cryorolled \& aged at } \\
160^{\circ} \mathrm{C} \text { (CRPA) }\end{array}$ & 34.96 & $3.28 \times 10^{-5}$ & 0.9 & 2294 & $4.55 \times 10^{-4}$ & 0.8 & 9810 & $1.898 \times 10^{9}$ \\
\hline $\begin{array}{l}\text { Solutionized \& aged at } \\
160^{\circ} \mathrm{C}(\mathrm{CGPA})\end{array}$ & 34.32 & $5.65 \times 10^{-5}$ & 0.9 & 2631 & $4.50 \times 10^{-4}$ & 0.9 & 7155 & $6.925 \times 10^{4}$ \\
\hline
\end{tabular}




\subsection{Intergranular corrosion (IGC)}

The combined effect of pitting and IGC leads to localized corrosion in $\mathrm{Al}$ alloys [42]. IGC is a type of localized attack that occurs because of the enhanced tendency toward corrosion relative to the tendency of the grain matrix, at and adjacent to the grain boundaries [43]. The tendency toward corrosion increases with precipitation of S-phase anodic particles in the grain boundaries or with the depletion of $\mathrm{Cu}$ from the surrounding matrix [44]. The coarse precipitates of $\mathrm{Al}_{2} \mathrm{CuMg}$, forming a continuous network along the grain boundaries, in the CGPA alloy undergo selective dissolution of $\mathrm{Mg}$, with respect to the PFZ and matrix, leading to a large amount of material loss and finally resulting in fallout of the grains. Krishna et al. have reported similar observations in a localized corrosion study of $\mathrm{Al}-\mathrm{Zn}-\mathrm{Mg}-(\mathrm{Cu})$ alloys [25]. Thus, on the basis of the compositional or structural heterogeneity, IGC occurs in these pre-existing active dissolution paths.

After IGC immersion testing for $24 \mathrm{~h}$, the samples showed substantial attack, as shown in Fig. 14. The solutio-
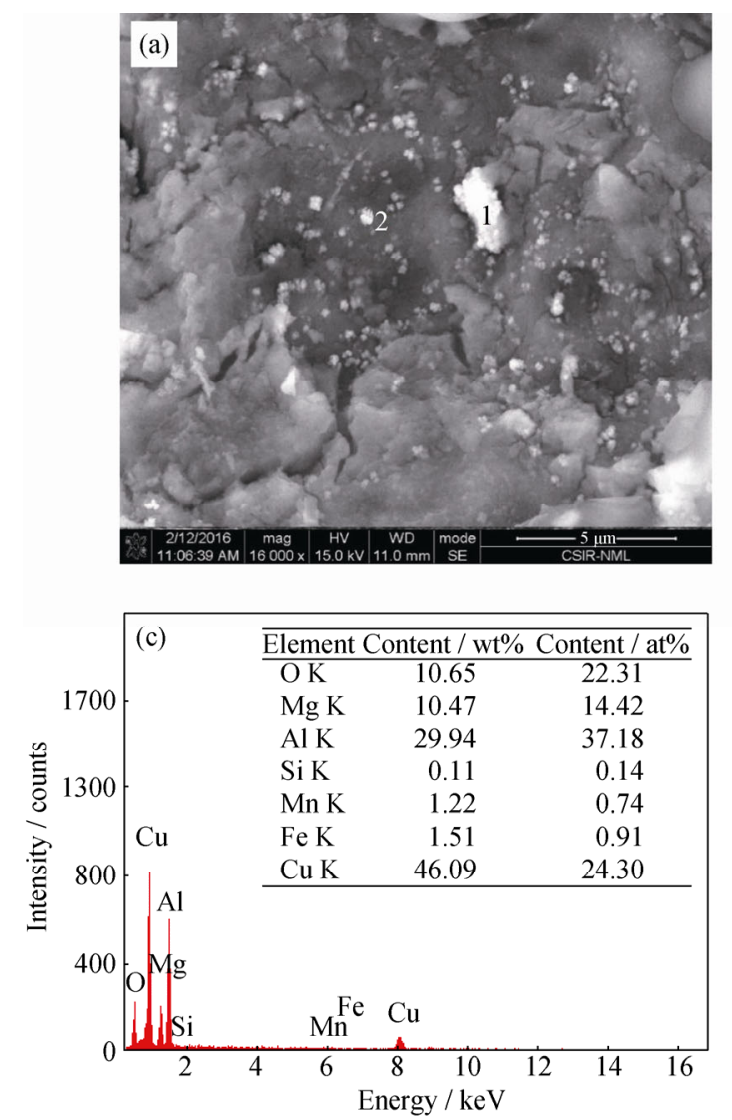

nized and aged sample exhibited grain-boundary attack along with the coarse pits within the grains. The EDS as shown in Fig. 14(c) for the particles adjacent to the grain boundary (marked as 1 in Fig. 14(b)) reveals the enrichment of $\mathrm{Cu}$ by selective dissolution of S-phase particles with respect to the PFZs and the matrix. The CRPA alloy showed a clear change in the attack morphology compared with that in the case of the CGPA alloy. The extent of corrosion damage is homogeneous in the CRPA alloy because of the uniform distribution of precipitates, as evident from the SEM image in Fig. 14(a). The results obtained from the mass-loss measurements in Table 5 explain the decreased susceptibility of the CRPA alloy toward IGC, where the CRPA alloy exhibited lower mass loss $\left((8.38 \pm 0.16) \mathrm{mg} / \mathrm{cm}^{2}\right)$ than the CGPA alloy $\left((9.28 \pm 0.17) \mathrm{mg} / \mathrm{cm}^{2}\right)$. Cryorolling and subsequent aging altered the microstructure in terms of the arrangement and distribution of precipitates. Because of the shearing process and large strains associated with the SPD, the initial grain boundaries and their unique arrangement of precipitates

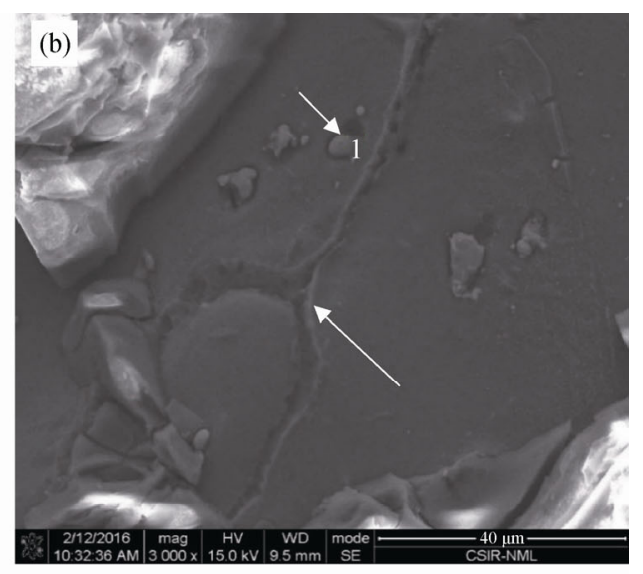

Fig. 14. SEM secondary electron images of AA2024 aluminum alloy samples: (a) CRPA alloy showing uniform attack; (b) CGPA alloy showing grain-boundary attack after IGC marked by the arrow, and " 1 " indicates a Cu-enriched precipitate after dealloying adjacent to a grain boundary; (c) corresponding EDS pattern for the particle marked as 1 in (b).

Table 5. Mass-loss measurement in intergranular corrosion (IGC) testing

\begin{tabular}{lccc}
\hline \multicolumn{1}{c}{ Sample } & Initial mass / g & Final mass / g & Mass loss / (mg.cm $\left.{ }^{-2}\right)$ \\
\hline Solutionized and aged at $160^{\circ} \mathrm{C}(\mathrm{CGPA})$ & 2.26196 & 2.18422 & $9.28 \pm 0.17$ \\
Cryorolled and aged at $160^{\circ} \mathrm{C}(\mathrm{CRPA})$ & 0.29201 & 0.23964 & $8.38 \pm 0.16$ \\
\hline
\end{tabular}


were destroyed. The SPD process in effect "desensitizes" the grain boundaries, and the dominant failure mode appears to be pitting, which is associated with the constituent particles [24].

\section{Conclusions}

The AA2024 alloy subjected to cryorolling to $85 \%$ thickness reduction exhibited an increase in hardness compared with that of the RT-rolled alloy. Subsequent aging of the rolled alloys at 130,160 , and $190^{\circ} \mathrm{C}$ resulted in enhanced aging kinetics compared with the solutionized and aged alloy samples. TEM observations of the cryorolled and aged alloy samples confirmed the formation of a UFG structure and the uniform distribution of finer strengthening S-phase $\left(\mathrm{Al}_{2} \mathrm{CuMg}\right)$ precipitates. Both (i) solutionized and (ii) solutionized and cryorolled alloys were uniformly aged at $160^{\circ} \mathrm{C}$ for $24 \mathrm{~h}$; the aged specimens were designated as CGPA and CRPA, respectively, and were subjected to further corrosion studies. A lower $i_{\text {corr }}$ for CRPA $((0.3809 \pm 0.1)$ $\left.\mu \mathrm{A} / \mathrm{cm}^{2}\right)$ compared with that for CGPA $((1.5079 \pm 0.4)$ $\mu \mathrm{A} / \mathrm{cm}^{2}$ ) confirmed the improvement in corrosion resistance for the CRPA alloy. Thus, cryorolling followed by aging of solutionized AA2024 alloy tends to form a UFG structure and result in the uniform distribution of fine strengthening precipitates; it also desensitizes the grain boundaries by avoiding the formation of coarse grain-boundary precipitates and associated PFZs, resulting in increased resistance to IGC.

\section{Acknowledgement}

Mr P. Laxman Mani Kanta would like to express his sincere gratitude to the Director, CSIR-National Metallurgical Laboratory, Jamshedpur for his kind permission and support to carry out major portion of this work at CSIR-NML.

\section{References}

[1] J.R. Davis, Corrosion of Aluminium and Aluminium Alloys, ASM International, Ohio, 1999, p. 1.

[2] A. Boag, A.E. Hughes, N.C. Wilson, A. Torpy, C.M. MacRae, A.M. Glenn, and T.H. Muster, How complex is the microstructure of AA2024-T3? Corros. Sci., 51(2009), No. 8, p. 1565.

[3] D.J. Chakrabarti and D.E. Laughlin, Phase relations and precipitation in $\mathrm{Al}-\mathrm{Mg}-\mathrm{Si}$ alloys with $\mathrm{Cu}$ additions, Prog. Mater. Sci., 49(2004), No. 3-4, p. 389.

[4] G. Sha, R.K.W. Marceau, X. Gao, B.C. Muddle, and S.P. Ringer, Nanostructure of aluminium alloy 2024: segregation, clustering and precipitation processes, Acta Mater., 59(2011), No. 4, p. 1659.

[5] G.E. Totten and D.S. Mackenzie, Handbook of Aluminum: Vol. 1: Physical Metallurgy and Processes, Marcel Dekker Inc, NY, USA, 2003, p.140.

[6] S.C. Wang, M.J. Starink, and N. Gao, Precipitation hardening in Al-Cu-Mg alloys revisited, Scripta Mater., 54(2006), No. 2, p. 287.

[7] R.Z. Valiev, Y. Estrin, Z. Horita, T.G. Langdon, M.J. Zechetbauer, and Y.T. Zhu, Producing bulk ultrafine-grained materials by severe plastic deformation: Ten years later, JOM, 68(2016), No. 4, p. 1216.

[8] T. Shanmugasundaram, B.S. Murty, and V.S. Sarma, Development of ultrafine grained high strength $\mathrm{Al}-\mathrm{Cu}$ alloy by cryorolling, Scripta Mater., 54(2006), No. 12, p. 2013.

[9] N. Rangaraju, T. Raghuram, B.V. Krishna, K.P. Rao, and P. Venugopal, Effect of cryo-rolling and annealing on microstructure and properties of commercially pure aluminium, Mater. Sci. Eng. A, 398(2005), No. 1-2, p. 246.

[10] P. Nageswara rao and R. Jayaganthan, Effects of warm rolling and ageing after cryogenic rolling on mechanical properties and microstructure of Al 6061 alloy, Mater. Des., 39(2012), p. 226.

[11] P.N. Rao, D. Singh, and R. Jayaganthan, Effect of post cryorolling treatments on microstructural and mechanical behaviour of ultrafine grained Al-Mg-Si alloy, J. Mater. Sci. Technol., 30(2014), No. 10, p. 998.

[12] S.K. Panigrahi and R. Jayaganthan, Effect of ageing on microstructure and mechanical properties of bulk, cryorolled, and room temperature rolled Al 7075 alloy, J. Alloys Compd., 2011(509), No. 40, p. 9609.

[13] P. Das, R. Jayaganthan, and I.V. Singh, Tensile and impact-toughness behaviour of cryorolled Al 7075 alloy, Mater. Des., 32(2011), No. 3, p. 1298.

[14] S.K. Panigrahi, R. Jayaganthan, and V. Pancholi, Effect of plastic deformation conditions on microstructural characteristics and mechanical properties of Al 6063 alloy, Mater. Des., 30(2009), No. 6, p. 1894.

[15] D. Devaiah, P. Venkatachalam, S.R. Kumar, B. Ravisankar, and $\mathrm{K}$. Jayashankar, Improving the mechanical properties of $2024 \mathrm{Al}$ alloy by cryorolling, Trans. Indian Inst. Met., 63(2010), No. 1, p. 31.

[16] K.G. Krishna, N. Singh, K. Venkateswarlu, and K.C.H. Kumar, Tensile behavior of ultrafine-grained $\mathrm{Al}-4 \mathrm{Zn}-2 \mathrm{Mg}$ alloy produced by cryorolling, J. Mater. Eng. Perform., 20(2011), No. 9, p. 1569.

[17] C.M. Li, N.P. Cheng, Z.Q. Chen, N. Guo, and S.M. Zeng, Deep-cryogenic-treatment-induced phase transformation in the $\mathrm{Al}-\mathrm{Zn}-\mathrm{Mg}-\mathrm{Cu}$ alloy, Int. J. Miner. Metall. Mater., 22(2015), No. 1, p. 68.

[18] G.S. Chen, M. Gao, and R.P. Wei, Microconstituent-induced pitting corrosion in aluminum alloy 2024-T3, Corros. Sci., 52(1996), No. 1, p. 8.

[19] C.M. Liao, J.M. Olive, M. Gao, and R.P. Wei, In-situ monitoring of pitting corrosion in aluminum alloy 2024, Corros. 
Sci., 54(1998), No. 6, p. 451.

[20] R.P. Wei, C.M. Liao, and M. Gao, A transmission electron microscopy study of constituent-particle-induced corrosion in 7075-T6 and 2024-T3 aluminum alloys, Metall. Mater. Trans. A, 29(1998), No. 4, p. 1153.

[21] J.H. Liu, M. Li, S.M. Li, and M. Huang, Effect of the microstructure of Al 7050-T7451 on anodic oxide formation in sulfuric acid, Int. J. Miner. Metall. Mater., 16(2009), No. 4, p. 432.

[22] S.M. Li, Y.D. Li, Y. Zhang, J.H. Liu, and M. Yu, Effect of intermetallic phases on the anodic oxidation and corrosion of 5A06 aluminum alloy, Int. J. Miner. Metall. Mater., 22(2015), No. 2, p. 167.

[23] J.G. Brunner, J. May, H.W. Höppel, M. Göken, and S. Virtanen, Localized corrosion of ultrafine-grained $\mathrm{Al}-\mathrm{Mg}$ model alloys, Electrochim. Acta, 55(2010), No. 6, p. 1966.

[24] J.G. Brunner, N. Birbilis, K.D. Ralston, and S. Virtanen, Impact of ultrafine-grained microstructure on the corrosion of aluminium alloy AA2024, Corros. Sci., 57(2012), p. 209.

[25] K.G. Krishna, K. Sivaprasad, T.S.N.S. Narayanan, and K.C.H. Kumar, Localized corrosion of an ultrafine grained $\mathrm{Al}-4 \mathrm{Zn}-2 \mathrm{Mg}$ alloy produced by cryorolling, Corros. Sci., 60(2012), p. 82.

[26] I.J. Son, H. Nakano, S. Oue, S. Kobayashi, H. Fukushima, and Z. Horita, Pitting corrosion resistance of anodized aluminium alloy processed by severe plastic deformation, Mater. Trans., 48(2007), No. 1, p. 21.

[27] K.G. Krishna, K. Sivaprasad, K. Venkateswarlu, and K.C.H. Kumar, Microstructural evolution and aging behavior of cryorolled Al-4Zn-2Mg alloy, Mater. Sci. Eng. A, 535(2012), p. 129.

[28] N.N. Krishna, R. Tejas, K. Sivaprasad, and K. Venkateswarlu, Study on cryorolled $\mathrm{Al}-\mathrm{Cu}$ alloy using $\mathrm{X}$-ray diffraction line profile analysis and evaluation of strengthening mechanisms, Mater. Des., 52(2013), p. 785.

[29] N.N. Krishna, B. Gopi, K. Sivaprasad, and V. Muthupandi, Studies on potentiodynamic polarization behaviour of cryorolled Al-Mg-Si alloy, Key Eng. Mater., 545(2013), p. 153.

[30] S.K. Panigrahi and R. Jayaganthan, Development of ultrafine-grained Al 6063 alloy by cryorolling with the optimized initial heat treatment conditions, Mater. Des., 32(2011), No. 4, p. 2172.

[31] T. Sakai, A. Belyakov, R. Kaibyshev, H. Miura, and J.J. Jonas, Dynamic and post-dynamic recrystallization under hot, cold and severe plastic deformation conditions, Prog. Mater. Sci., 60(2014), p. 130.
[32] R. Vafaei, M.R. Toroghinejad, and R. Pippan, Evaluation of mechanical behavior of nano-grained $2024 \mathrm{Al}$ alloy during high pressure torsion (HPT) process at various temperatures, Mater. Sci. Eng. A, 536(2012), p. 73.

[33] Y.C. Lin, Y.C. Xia, Y.Q. Jiang, H.M. Zhou, and L.T. Li, Precipitation hardening of 2024-T3 aluminum alloy during creep aging, Mater. Sci. Eng. A, 565(2013), p. 420.

[34] G. Kotan, E. Tan, Y.E. Kalay, and C.H. Gür, Homogenization of ECAPed Al 2024 alloy through age-hardening, $\quad M a-$ ter. Sci. Eng. A, 559(2013), p. 601.

[35] Z.Q. Feng, Y.Q. Yang, B. Huang, M. Han, X. Luo, and J.G. $\mathrm{Ru}$, Precipitation process along dislocations in $\mathrm{Al}-\mathrm{Cu}-\mathrm{Mg}$ alloy during artificial aging, Mater. Sci. Eng. A, 528(2010), No. 2, p. 706.

[36] T.S. Parel, S.C. Wang, and M.J. Starink, Hardening of an $\mathrm{Al}-\mathrm{Cu}-\mathrm{Mg}$ alloy containing Types I and II S-phase precipitates, Mater. Des., 31(2010), Supp. 1, p. S2.

[37] Y.L. Cheng, Z. Zhang, F.H. Cao, J.F. Li, J.Q. Zhang, J.M. Wang, and C.N. Cao, Study of the potential electrochemical noise during corrosion process of aluminum alloys 2024, 7075 and pure aluminium, Mater. Corros., 54(2003), No. 8, p. 601.

[38] K. Sivaprasad, V. Swarnalatha, V.V. Ravikumar, and V. Muthupandi, Influence of short annealing treatment on corrosion behaviour of cryorolled commercially pure aluminum, Anti-Corros. Methods Mater., 57(2010), No. 1, p. 18.

[39] Y.J. Liu, Z.Y. Wang, and W. Ke, Study on influence of native oxide and corrosion products on atmospheric corrosion of pure Al, Corros. Sci., 80(2014), p. 169.

[40] Y.L. Cheng, Z. Zhang, F.H. Cao, J.F. Li, J.Q. Zhang, J.M. Wang, and C.N. Cao, A study of the corrosion of aluminum alloy 2024-T3 under thin electrolyte layers, Corros. Sci., 46(2004), No. 7, p. 1649.

[41] W.J. Lorenz and F. Mansfeld, Determination of corrosion rates by electrochemical DC and AC methods, Corros. Sci., 21(1981), No. 9-10, p. 647

[42] K.S. Ghosh, M. Hilal, and B.O.S.E. Sagnik, Corrosion behavior of 2024 Ai CüMg alloy of various tempers, Trans. Nonferrous Met. Soc. China, 23(2013), No. 11, p. 3215.

[43] D.A. Little, B.J. Connolly, and J.R. Scully, An electrochemical framework to explain the intergranular stress corrosion behavior in two $\mathrm{Al}-\mathrm{Cu}-\mathrm{Mg}-\mathrm{Ag}$ alloys as a function of aging, Corros. Sci., 49(2007), No. 2, p. 347.

[44] R.G. Buchheit, R.P. Grant, P.F. Hlava, B. McKenzie, and G.L. Zender, Local dissolution phenomena associated with $\mathrm{S}$ phase $\left(\mathrm{Al}_{2} \mathrm{CuMg}\right)$ particles in aluminum alloy 2024-T3, $J$. Electrochem. Soc., 144(1997), No. 8, p. 2621. 